\title{
An evaluation of CD39 as a novel immunoregulatory mechanism invoked by COPD
}

Dino BA Tan ${ }^{1,2}$, Nathanael E Ong ${ }^{2}$, Maja Zimmermann², Patricia Price ${ }^{3}$, Yuben P Moodley ${ }^{1,2,4}$

${ }^{1}$ Centre for Respiratory Health, School of Medicine \& Pharmacology, University of Western Australia, Nedlands, WA, Australia

${ }^{2}$ Stem Cell Unit, Institute of Respiratory Health, Nedlands, WA, Australia

${ }^{3}$ School of Biomedical Science, Curtin University, Bentley, WA, Australia

${ }^{4}$ Department of Respiratory and Sleep Medicine, Royal Perth Hospital, Perth, WA, Australia

\section{Corresponding author:}

Dr. Dino Bee Aik Tan

Level 2, Medical Research Foundation Building

Royal Perth Hospital,

Rear 50 Murray Street,

Perth, WA 6000, Australia

Email: dino.tan@uwa.edu.au

Phone: +61892240270 


\begin{abstract}
Acute exacerbations of chronic obstructive pulmonary disease (AECOPD) are characterized by increased pulmonary and systemic inflammation and commonly caused by bacterial and/or viral infection. Little is known about the T-cell dysregulation in AECOPD that promotes these outcomes. CD39 is an ectonucleotidase able to hydrolyse adenosine triphosphate to create adenosine that may inhibit T-cell responses in patients with AECOPD. Here T-cell expression of CD39 measured by flow cytometry was higher in AECOPD patients than stable COPD patients or healthy controls. Higher expression of CD39 was associated with higher levels of plasma soluble tumor necrosis factor receptor but lower interferon- $\gamma$ (IFN $\gamma$ ) levels in supernatants from staphylococcal enterotoxin-B stimulated peripheral blood mononuclear cells. This links increased expression of CD39 with systemic inflammation and impaired T-cell responses (e.g. IFN $\gamma$ ). The blockade of CD39 pathways may be a novel approach to the control of AECOPD, reducing the dependency on antibiotics.
\end{abstract}

Keywords: AECOPD; CD39; COPD; IFN $\gamma$; T-cell 


\section{Introduction}

Chronic obstructive pulmonary disease (COPD) is amongst the top five causes of global morbidity and mortality. COPD is characterized by chronic airway and systemic inflammation and so predisposes patients to ischemic heart disease, vascular disease, muscle wasting and cachexia [1, 2]. COPD patients may also experience acute exacerbations (AECOPD), commonly caused by infections [3]. AECOPD can accelerate the decline in lung function [4], but the associated immune dysregulation is not well understood. AECOPD may be an immune-deficient state reflecting an impaired T-helper type I (Th1) responses to infectious agents (e.g. decreased production of IFN $\gamma$ ) [59]. There are several anti-inflammatory molecules, including CD39 that may be highly expressed in AECOPD that may inhibit IFN $\gamma$ responses.

CD39 is an ectonucleotidase which generates adenosine monophosphate (AMP) from adenosine triphosphate/adenosine diphosphate (ATP/ADP). CD73 (another ectonucleotidase) then converts AMP to adenosine, an anti-inflammatory molecule that can inhibit the function of $\mathrm{CD}^{+}$and $\mathrm{CD} 8^{+}$ T-cells and natural killer cells [10]. CD39 is highly expressed by regulatory T-cells (Tregs) and is important for their immune-suppressive function [11, 12]. Inflammation usually results in the release of ATP that is converted to adenosine by Tregs via the CD39/CD73 pathway. The binding of adenosine to $\mathrm{A}_{2 \mathrm{~A}}$ receptors downregulates the activity of effector T-cells but promotes the expansion of Tregs and their suppression of effector T-cell proliferation [13].

Therefore, CD39 and CD73 are important in the regulation of immune responses by inhibiting the ATP-driven pro-inflammatory immune cell activity and promote an anti-inflammatory state mediated by adenosine [10]. Since AECOPD may be an immunodeficient state, we hypothesized that chronic inflammation induces the expression of CD39 that then inhibits protective effector T-cell responses (e.g. IFN $\gamma$ production) against bacteria in AECOPD. 


\section{Material and methods}

\subsection{Study subjects}

AECOPD patients $(n=21)$ admitted to the Royal Perth Hospital Emergency Department (Western Australia) were recruited. Stable COPD (sCOPD) patients who were previous smokers (>15 packyears and ceased smoking >5 years earlier) from a dedicated Royal Perth Hospital COPD clinic $(n=33)$ and healthy age-matched, non-smoking subjects with no clinical evidence of COPD were also included as controls $(n=33)$. The diagnosis and severity of COPD was categorised by a respiratory physician according to the GOLD criteria (Stages 2-4). All patients had been treated with anticholinergic drugs, long-acting beta agonists and inhaled corticosteroids but none were receiving systemic corticosteroids or had diabetes, neuromuscular, allergic or rheumatological disease at the time of sampling. The study was approved by the Ethics Committee at the Royal Perth Hospital and all participants gave informed consent.

\subsection{Sample and data collection}

Peripheral blood mononuclear cells (PBMC) were isolated from blood collected in lithium heparin tubes by Ficoll gradient centrifugation and cryopreserved in $10 \%$ dimethyl sulfoxide/fetal calf serum. Plasma was stored at $-80^{\circ} \mathrm{C}$. Plasma levels of IL-6, C-reactive protein (CRP) and sTNFR were measured by ELISA (R\&D Systems, Minneapolis, MN). Proportions of CD39+ ${ }^{+}$-cells were quantified by flow cytometry after staining PBMC with anti-CD3-APC-H7, CD4-V500, CD8-PerCPCy5.5, CD39-FITC, CD28-PE-Cy7 and PD-1-APC antibodies (BD Biosciences, San Jose, CA). Intracytoplasmic staining was performed using the BD Pharmingen ${ }^{\mathrm{TM}}$ FoxP3 buffer set and FoxP3PE antibody (BD Biosciences). 200,000 events were acquired using a BD FACSCanto II cytometer and analyses were done with FlowJo v5.7.2 software (Tree Star, Ashland, OR). Gating for T-cell subsets and expression of CD39 is shown in Figure 1. Concentrations of IFN $\gamma$, TNF $\alpha$, IL-6, IL-10 (BD Biosciences) and IL-17 (eBioscience, San Diego, CA) were measured by ELISA in supernatants from PBMC $\left(2 \times 10^{6}\right.$ cells $\left./ \mathrm{mL}\right)$ cultured with SEB $(1 \mu \mathrm{g} / \mathrm{mL}$; Sigma-Aldrich, St. Louis, MO) for $24 \mathrm{hr}$. 


\subsection{Data Analysis}

Non-parametric Mann-Whitney tests were used to compare groups. Correlations were assessed using Spearman's rank correlation coefficient. Statistical analyses were performed with Graphpad Prism 5.04 software (La Jolla, CA). Statistically significant differences $(\mathrm{p}<0.05)$ are indicated in the figures and $\mathrm{p}=0.05-0.10$ is noted as marking a trend.

\section{Results}

3.1 AECOPD patients exhibited systemic inflammation but decreased SEB-induced IFNy production

Stable COPD (sCOPD) and AECOPD patients had elevated plasma levels of CRP ( $\mathrm{p}=0.004 \&$ $\mathrm{p}<0.001$, respectively), IL-6 ( $\mathrm{p}=0.001 \& \mathrm{p}=0.003$, resp.) and sTNFR ( $\mathrm{p}=0.007 \& \mathrm{p}<0.001$, resp.) when compared to healthy controls (Figure 2, A-C). AECOPD patients had marginally higher plasma CRP ( $\mathrm{p}=0.07)$, IL-6 $(\mathrm{p}=0.09)$ and sTNFR $(\mathrm{p}=0.04)$ than sCOPD patients.

Following stimulation with SEB, levels of IFN $\gamma$, TNF $\alpha$ and IL-6 was lower in PBMC from AECOPD patients than $\mathrm{SCOPD}$ patients $(\mathrm{p}=0.0001-0.002)$ and healthy controls $(\mathrm{p}=0.0004-0.005)$ (Figure 2 , DF). The production of IL-17 and IL-10 was lower in AECOPD patients than controls ( $\mathrm{p}=0.05$ for both) and $\mathrm{sCOPD}$ patients ( $\mathrm{p}=0.06$ and $\mathrm{p}=0.002$, respectively) (Figure $2 \mathrm{G}$ and $2 \mathrm{H}$ ). Level of plasma sTNFR showed weak to moderate negative associations with the levels of IFN $\gamma(\mathrm{r}=-0.23, \mathrm{p}=0.07)$, IL-6 $(\mathrm{r}=-$ 0.23, $\mathrm{p}=0.07), \mathrm{IL}-17(\mathrm{r}=-0.31, \mathrm{p}=0.04)$ and IL-10 $(\mathrm{r}=-0.32, \mathrm{p}=0.02)$ in culture supernatants.

\subsection{Expression of CD39 on T-cells correlates directly with plasma STNFR and inversely with IFN $\gamma$ production by $\mathrm{T}$-cells}

Proportions of circulating CD39 ${ }^{+} \mathrm{CD}^{+}$and $\mathrm{CD} 8^{+} \mathrm{T}$-cells, Tregs (Foxp3 ${ }^{+} \mathrm{CD}^{+} \mathrm{T}$-cells) and nonTregs (Foxp3- CD4 ${ }^{+}$T-cells) were higher in AECOPD patients than sCOPD patients (Figure 3A). Compared to healthy controls, AECOPD patients exhibited increased proportion of CD $39^{+} \mathrm{CD}^{+} \mathrm{T}$ - 
cells $(\mathrm{p}=0.008)$ and marginal higher proportion of $\mathrm{CD} 39^{+} \mathrm{CD} 4^{+} \mathrm{T}$-cells $(\mathrm{p}=0.08)$. Furthermore, plasma sTNFR correlated directly with proportions of $\mathrm{CD} 39^{+} \mathrm{CD}^{+} \mathrm{T}$-cells $(\mathrm{r}=0.25, \mathrm{p}=0.048)$ and $\mathrm{CD}^{+} \mathrm{T}$-cells $(\mathrm{r}=0.28, \mathrm{p}=0.027)$. The proportion of $\mathrm{CD} 39^{+} \mathrm{T}$-cells correlated inversely with the levels of IFN $\gamma$ produced by SEB-stimulated PBMC (Figure 3, B-E), but not with levels of TNF $\alpha$, IL-6, IL17 and IL-10 (data not shown).

\section{Discussion}

This study describes for the first time the expression of CD39 on circulating T-cell subsets in relation to systemic inflammation and cytokine responses of patients with stable COPD or AECOPD. Our data demonstrated that the proportion of CD39-expressing $\mathrm{CD}^{+}, \mathrm{CD}^{+}, \mathrm{Foxp}^{+}$(Tregs) and FoxP3T-cells were increased in the circulation of AECOPD patients. This increase was associated with systemic inflammation as evidenced by a correlation with plasma levels of sTNFR. Furthermore, PBMC from AECOPD patients had impaired production of cytokines important for bacterial clearance such as IFN $\gamma, \mathrm{TNF} \alpha$, IL-6 and IL-17. Proportions of CD39+ ${ }^{+}$-cells correlated inversely with SEB-induced IFN $\gamma$ responses. This is in line with the findings with other inflammatory conditions which support a role for the CD39 and associated purinergic signalling pathways in inhibiting immune responses during chronic inflammation.

Increased numbers of $\mathrm{CD} 39^{+}$cells that may provide anti-inflammatory functions have been isolated in inflammatory sites such as joints of arthritic patients [14], bronchoalveolar lavage from COPD patients [15], and lamina propria of patients with Crohn's disease [16]. Circulating antigen-reactive $\mathrm{CD}^{+}$T-cells expressing CD39 were also increased in patients with active rather than latent tuberculosis [17]. There is growing evidence to suggest that CD39 inhibits IFN $\gamma$ production. Notably depletion of $\mathrm{CD} 9^{+}$Treg increased TB-specific antigen responses [18]. Furthermore, Bai et al demonstrated that $\mathrm{CD} 9^{+} \mathrm{CD}^{+} \mathrm{T}$-cells inhibited IFN $\gamma$ production by $\mathrm{CD} 39^{-} \mathrm{CD}^{+} \mathrm{T}$-cells from healthy control samples [16]. 
Increased expression of CD39 has also been associated with other markers of T-cell exhaustion or dysfunction. This includes increased expression of PD-1 paralleling the decreased expression of CD28 and production of IFN $\gamma$ [19]. In our patient cohort, we correlated increased CD28 ${ }^{\text {null }} \mathrm{T}$-cells in COPD and AECOPD with CMV-IgG titres [20]. Here increased expression of CD39 correlated with the loss of CD28 expression on $\mathrm{CD}^{+} \mathrm{T}$-cells $(\mathrm{r}=-0.245, \mathrm{p}=0.047)$ and increased PD-1 expression $(\mathrm{r}=0.278, \mathrm{p}=0.024)$. Within the Treg population, expression of CD39 also correlated with the expression of PD-1 ( $\mathrm{r}=0.882, \mathrm{p}=0.004)$. The data suggest that CD39 may promote immune exhaustion in patients with COPD and so contribute to the suppression of protective immune responses.

Our results build on the work by Lazar et al (2015) showing increased expression of CD39 on cells from bronchoalveolar lavage fluid and sputum of ex-smoking COPD patients than smokers and nonsmoking controls [15]. They demonstrated that cigarette smoking induces the expression of CD39 on bronchoalveolar lavage cells and lung tissue, and proposed a compensatory upregulation of CD39 as a protective mechanism in cigarette smoke-induced lung damage. Our data suggests that the increased CD39 expression is not only limited to the lung environment but is also evident systemically, possibly as a compensatory response to chronic inflammation in COPD resulting in poorer T-cell responses. Blockade of CD39 may restore T-cell responses, but abrogation of CD39 in knockout mice promoted emphysema [15], and cigarette smoke can reduce CD39 expression in the lung, macrophages and vascular endothelial cells [21]. Therefore, further studies and refinements are required before CD39 is accepted as an appropriate theraupeutic target,.

\section{ACKNOWLEDGEMENTS}

This work was supported by an Ada Bartholomew Medical Research Trust Grant from the Faculty of Medicine, Dentistry and Health Sciences, University of Western Australia and a MRF Young Investigator Grant from Royal Perth Hospital. The authors would like to thank the staff at the Centre 
for Clinical Research in Emergency Medicine, Harry Perkins Institute of Medical Research and the COPD Linkage clinic, Royal Perth Hospital for patient recruitment, and the patients and controls who volunteered for this study. The authors also acknowledge the contributions of V. Seenarain, E. Dikstaal and A. Anderson who collected some laboratory data as part of their research component of the UWA Medical course. 


\section{REFERENCES}

1. Vestbo J, Hurd SS, Agusti AG, Jones PW, Vogelmeier C, Anzueto A et al. Global strategy for the diagnosis, management, and prevention of chronic obstructive pulmonary disease: GOLD executive summary. Am J Respir Crit Care Med 2013. 187: 347-365.

2. Barnes PJ and Celli BR. Systemic manifestations and comorbidities of COPD. Eur Respir J 2009. 33: 1165-1185.

3. Sethi S, Evans N, Grant BJ, and Murphy TF. New strains of bacteria and exacerbations of chronic obstructive pulmonary disease. N Engl J Med 2002. 347: 465-471.

4. Soler-Cataluna JJ, Martinez-Garcia MA, Roman Sanchez P, Salcedo E, Navarro M, and Ochando R. Severe acute exacerbations and mortality in patients with chronic obstructive pulmonary disease. Thorax 2005. 60: 925-931.

5. Berenson CS, Garlipp MA, Grove LJ, Maloney J, and Sethi S. Impaired phagocytosis of nontypeable Haemophilus influenzae by human alveolar macrophages in chronic obstructive pulmonary disease. J Infect Dis 2006. 194: 1375-1384.

6. King P, Ngui J, Oppedisano F, Robins-Browne R, Holmes P, and Holdsworth S. Effect of interferon gamma and CD40 ligation on intracellular monocyte survival of nontypeable Haemophilus influenzae. APMIS 2008. 116: 1043-1049.

7. Taylor AE, Finney-Hayward TK, Quint JK, Thomas CM, Tudhope SJ, Wedzicha JA et al. Defective macrophage phagocytosis of bacteria in COPD. Eur Respir J 2010. 35: 1039-1047.

8. Abe Y, Murphy TF, Sethi S, Faden HS, Dmochowski J, Harabuchi Y et al. Lymphocyte proliferative response to P6 of Haemophilus influenzae is associated with relative protection from exacerbations of chronic obstructive pulmonary disease. Am J Respir Crit Care Med 2002. 165: 967-971.

9. Knobloch J, Schild K, Jungck D, Urban K, Muller K, Schweda EK et al. The T-helper cell type 1 immune response to gram-negative bacterial infections is impaired in COPD. Am J Respir Crit Care Med 2011. 183: 204-214. 
10. Antonioli L, Pacher P, Vizi ES, and Hasko G. CD39 and CD73 in immunity and inflammation. Trends Mol Med 2013. 19: 355-367.

11. O'Garra A and Vieira P. Regulatory T cells and mechanisms of immune system control. Nat Med 2004. 10: 801-805.

12. Borsellino G, Kleinewietfeld M, Di Mitri D, Sternjak A, Diamantini A, Giometto R et al. Expression of ectonucleotidase CD39 by Foxp3+ Treg cells: hydrolysis of extracellular ATP and immune suppression. Blood 2007. 110: 1225-1232.

13. Deaglio S, Dwyer KM, Gao W, Friedman D, Usheva A, Erat A et al. Adenosine generation catalyzed by CD39 and CD73 expressed on regulatory T cells mediates immune suppression. J Exp Med 2007. 204: 1257-1265.

14. Moncrieffe H, Nistala K, Kamhieh Y, Evans J, Eddaoudi A, Eaton S et al. High expression of the ectonucleotidase CD39 on $\mathrm{T}$ cells from the inflamed site identifies two distinct populations, one regulatory and one memory T cell population. J Immunol 2010. 185: 134143.

15. Lazar Z, Mullner N, Lucattelli M, Ayata CK, Cicko S, Yegutkin GG et al. NTPDase1/CD39 and aberrant purinergic signalling in the pathogenesis of COPD. Eur Respir J 2015.

16. Bai A, Moss A, Rothweiler S, Serena Longhi M, Wu Y, Junger WG et al. NADH oxidasedependent CD39 expression by CD8(+) T cells modulates interferon gamma responses via generation of adenosine. Nat Commun 2015. 6: 8819.

17. Kim K, Perera R, Tan DB, Fernandez S, Seddiki N, Waring J et al. Circulating mycobacterialreactive CD4+ T cells with an immunosuppressive phenotype are higher in active tuberculosis than latent tuberculosis infection. Tuberculosis (Edinb) 2014. 94: 494-501.

18. Chiacchio T, Casetti R, Butera O, Vanini V, Carrara S, Girardi E et al. Characterization of regulatory $\mathrm{T}$ cells identified as $\mathrm{CD} 4(+) \mathrm{CD} 25($ high$) \mathrm{CD} 39(+)$ in patients with active tuberculosis. Clin Exp Immunol 2009. 156: 463-470. 
19. Gupta PK, Godec J, Wolski D, Adland E, Yates K, Pauken KE et al. CD39 Expression Identifies Terminally Exhausted CD8+ T Cells. PLoS Pathog 2015. 11: e1005177.

20. Tan DB, Amran FS, Teo TH, Price P, and Moodley YP. Levels of CMV-reactive antibodies correlate with the induction of CD28 T cells and systemic inflammation in chronic obstructive pulmonary disease (COPD). Cell Mol Immunol 2015.

21. Kratzer A, Salys J, Sévigny J, Zamora M, and Taraseviciene-Stewart L. Second hand smoke exposure impairs CD39 expression and function in the lung. European Respiratory Journal 2012. 40. 


\section{FIGURE LEGENDS}

Figure 1 - Gating strategies used to identify CD39+ ${ }^{+}$-cell subsets: (A) Singlets were gated based on the expression of forward scatter-area (FCS-A) and FCS-Height. (B) Dead cells were then excluded and (C) lymphocytes were gated based on the expression of side scatter (SSC)-A and FSCA. (D) $\mathrm{CD}^{+}$or (E) $\mathrm{CD}^{+} \mathrm{T}$-cells were identified by co-expression of CD3 with CD4 or CD8 respectively. (F) Co-expression of CD39 and Foxp3 from $\mathrm{CD}^{+}{ }^{+} \mathrm{T}$-cells.

Figure 2 - Increased plasma biomarkers of inflammation but decreased production of IFN $\gamma$ by PBMC in AECOPD patients. A) CRP, B) IL-6 and C) sTNFR in plasma and levels of (D) IFN $\gamma$, (E) TNF $\alpha$, (F) IL-6, (G), IL-17 and (H) IL-10 in supernatants of PBMC+SEB cultures were measured by ELISA. $* * * \mathrm{p}<0.001, * * \mathrm{p}<0.01, * \mathrm{p}<0.05$, Mann-Whitney t-test.

Figure 3 - Frequencies of CD39 expressing T-cells were elevated in AECOPD patients and associate with decreased production of IFN $\gamma$ in response to SEB. (A) Proportion of CD39+ cells (as a $\%$ of parent population). (B-E) Correlation of IFN $\gamma$ level in supernatants with proportion of CD39-expressing T-cell subsets. ${ }^{* *} \mathrm{p}<0.001,{ }^{* *} \mathrm{p}<0.01,{ }^{*} \mathrm{p}<0.05$, Mann-Whitney t-test. 


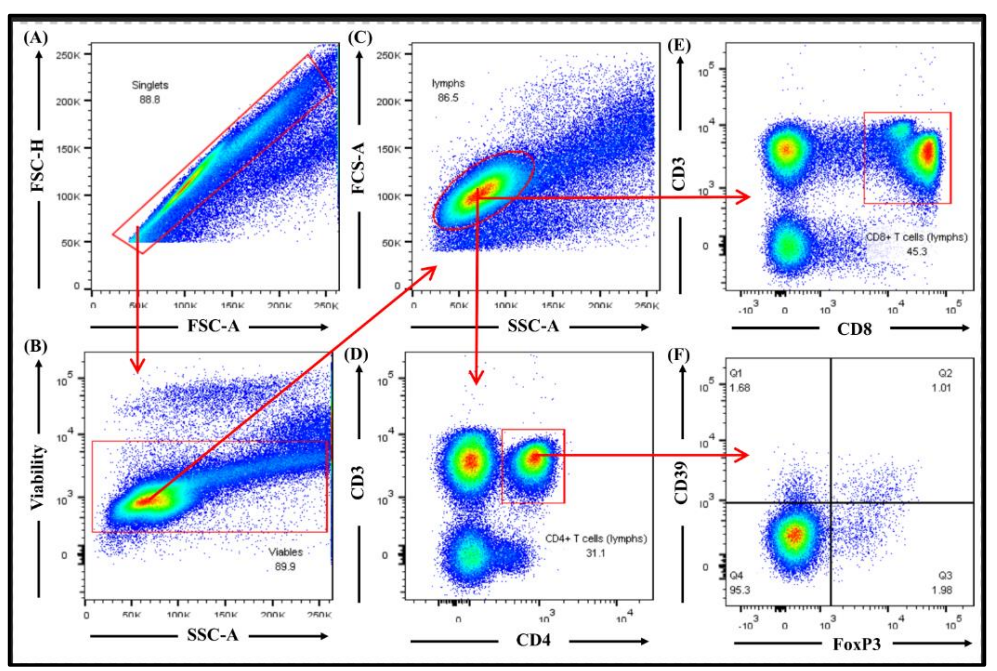

Figure 1

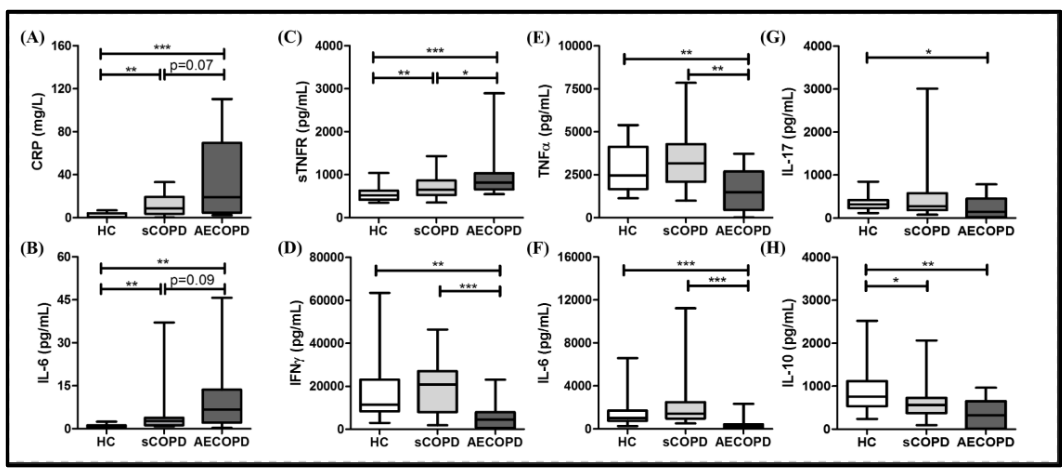

Figure 2

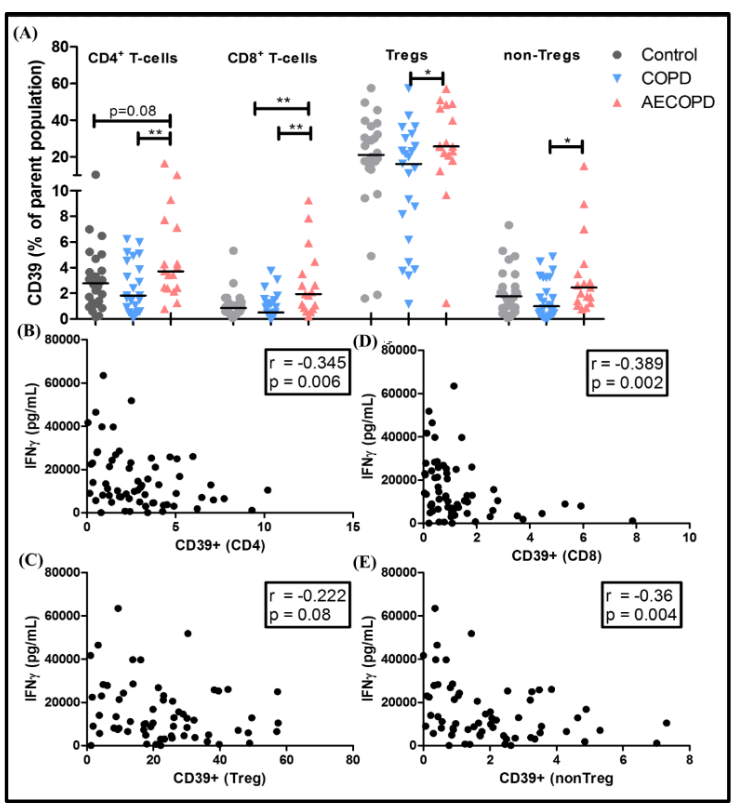

Figure 3 